\title{
Stereochemistry and Accessibility of Prosthetic Groups in Flavoproteins ${ }^{\dagger}$
}

\author{
Dietmar J. Manstein, ${ }^{\dagger,}$ Vincent Massey, $"$ Sandro Ghisla, ${ }^{\perp}$ and Emil F. Pai ${ }^{*, \downarrow}$ \\ Abteilung Biophysik, Max-Planck-Institut für Medizinische Forschung, Jahnstrasse 29, D-6900 Heidelberg, Federal Republic \\ of Germany, Department of Biological Chemistry, The University of Michigan, Ann Arbor, Michigan 48109, and Fakultät für \\ Biologie, Universität Konstanz, D-7750 Konstanz, Federal Republic of Germany
}

\begin{abstract}
Using 8-demethyl-8-hydroxy-5-deaza-5-carba analogues of the appropriate flavin nucleotides, we determined the stereochemistry of interaction between coenzyme and substrate for several flavoproteins. The enzymes were D-amino acid oxidase, L-lactate oxidase, and D-lactate dehydrogenase, all three of which interact with pyruvate, as well as cyclohexanone monooxygenase and 2-methyl-3-hydroxypyridine-5-carboxylic acid oxygenase, which were both probed with nicotinamide nucleotides. L-Lactate oxidase and D-lactate dehydrogenase used the $s i$ face of the modified flavin ring while the other three enzymes showed re-side specificity. This selection of flavoenzymes includes FAD- and FMN-dependent enzymes, enzymes that follow a carbanion mechanism, and others that have hydride transfer as an integral part of their reaction pathway.
\end{abstract}

8-Demethyl-8-hydroxy-5-deaza-5-carbariboflavin (Ashton \& Brown, 1980) is a flavin analogue whose specific features make it well suited for probing stereospecificities of flavin coenzymes in enzymic reactions. Its shape and charge usually do not interfere with binding at active sites of enzymes; it can be transformed to the FMN and FAD levels, respectively, by the well-characterized riboflavin kinase/FAD synthetase from Brevibacterium ammoniagenes (Spencer et al., 1976; Manstein

\footnotetext{
+Supported, in part, by Grant GM-11106 from the U.S. Public Health Service and Grants Gh-2/5-1 and Ma-1081/1-1 from the Deutsche Forschungsgemeinschaft

¥ Max-Planck-Institut für Medizinische Forschung.

Present address: Department of Cell Biology, Stanford University

School of Medicine, Stanford, CA 94305.

"The University of Michigan.

$\perp$ Universität Konstanz.
}

\& Pai, 1986); it is stable against reoxidation by air; it does not show the rapid two-electron disproportionation found in mixtures of oxidized and reduced 5-deazaflavins ${ }^{1}$ (Spencer et al., 1976).

In the previous paper of this series (Manstein et al., 1986) we described a method for determining the stereochemistry

\footnotetext{
1 Abbreviations: MHPC-oxygenase, 2-methyl-3-hydroxypyridine-5carboxylic acid oxygenase; $\mathrm{AcPyAD}^{+}$, oxidized 3-acetylpyridine adenine dinucleotide; AcPyADP ${ }^{+}$, oxidized 3-acetylpyridine adenine dinucleotide phosphate; 5-deazaflavin, 5-deaza-5-carbaisoalloxazine; 8-OH-5-deazaflavin, 8-demethyl-8-hydroxy-5-deaza-5-carbaisoalloxazine; $\left[5-{ }^{3} \mathrm{H}\right]$ 8-OH-5-deazaFADH ${ }_{2}$, reduced 8-OH-5-deazaFAD with one tritium label at carbon 5; Tris- $\mathrm{HCl}$, tris(hydroxymethyl)aminomethane hydrochloride; MES, 2-( $N$-morpholino)ethanesulfonic acid; DTT, dithiothreitol; EDTA, ethylenediaminetetraacetic acid; HPLC, high-pressure liquid chromatography.
} 
of substrate-flavin interaction in flavoproteins, employing this $\mathrm{O}_{2}$-stable flavin analogue. The method relies on comparison of results obtained with different flavoenzymes to the results obtained with human erythrocyte glutathione reductase. The stereochemistry of flavine-pyridine nucleotide interaction in the latter enzyme is known from the X-ray crystal structures of several reaction intermediates (Pai \& Schulz, 1983). By use of this approach the stereospecificity of eight flavoenzymes has been reported: glutathione reductase, mercuric reductase, thioredoxin reductase, $p$-hydroxybenzoate hydroxylase, melilotate hydroxylase, anthranilate hydroxylase, glucose oxidase, and general acyl-CoA dehydrogenase. For all of these enzymes the substrate reacted on the re face of the flavin. Similarly, the NADH-FMN oxidoreductase from Beneckea harveyi had been reported to show interaction between the pyridine nucleotide and the flavin on the re face of the isoalloxazine ring (Yamazaki et al., 1980, 1985). Thus all flavoenzymes so far tested which employ the traditional flavin coenzymes showed re-side stereospecificity. On the other hand, several enzymes isolated from methanogenic bacteria which use 7,8-didemethyl-8-hydroxy-5-deazaflavin compounds as natural coenzymes were shown to employ the $s i$ face of the flavin in interaction with substrate (Yamazaki et al., 1985). Most of the re-side specific flavoproteins previously characterized operate by hydride-transfer mechanisms, use pyridine nucleotides as substrates, or have FAD as the native coenzyme. Thus it was of particular interest to extend the stereospecificity studies to different classes of flavoproteins, in order to determine if re-side stereospecificity is a general characteristic of traditional flavin coenzymes. In the present study we have extended the list of flavoproteins to include some which are generally recognized to proceed via a carbanion mechanism, e.g., D-amino acid oxidase, L-lactate oxidase, and D-lactate dehydrogenase [see Massey and Ghisla (1983) for a review], as well as one which employs FMN rather than FAD as the native coenzyme (L-lactate oxidase). The results clearly show that flavoproteins may interact with their substrate from either the re side or the si side, depending on the individual flavoprotein. The results also show that regardless of the type of reaction catalyzed, information can be obtained concerning the relative orientation of substrate and flavin in the enzyme active center.

\section{EXPERIMENTAL PROCEDURES}

\section{Materials}

3-Acetylpyridine adenine dinucleotides were obtained from P-L Biochemicals. Aquasolve scintillation fluid and $\mathrm{NaB}^{3} \mathrm{H}_{4}$ (lots $1953-227$ and $2273-183 ; 8 \mathrm{mCi} / \mathrm{mg}$ ) were from $\mathrm{New}$ England Nuclear. Naja naja venom, dithiothreitol, and charcoal Norit A were purchased from Sigma. 8-OH-5deazaFAD and 8-OH-5-deazaFMN were prepared as described previously (Manstein et al., 1986). All other chemicals were of the highest purity commercially available.

\section{Methods}

Enzymes and Apoenzymes. The following enzymes and apoenzymes were prepared as previously described: D-lactate dehydrogenase from Megasphera elsdenii (Olson \& Massey, 1979); L-lactate oxidase from Mycobacterium smegmatis (Choong et al., 1975; Sullivan et al., 1977); glucose oxidase from Aspergillus niger (Swoboda \& Massey, 1965; Swoboda, 1969); D-amino acid oxidase (Curti et al., 1973; Massey \& Curti, 1966) and general acyl-CoA dehydrogenase (Thorpe et al., 1979; Mayer \& Thorpe, 1981) from pig kidney.

2-Methyl-3-hydroxypyridine-5-carboxylic acid oxygenase (MHPC-oxygenase) from Pseudomonas sp. MA-1 was prepared by a new method, which will be published elsewhere $(P$.
Brissette, D. P. Ballou, and V. Massey, unpublished results). Apoenzyme was prepared by mixing a $30 \mu \mathrm{M}$ solution of the enzyme in $20 \mathrm{mM}$ potassium phosphate- $0.3 \mathrm{mM}$ EDTA, $\mathrm{pH}$ 6.8 , with 10 volumes of resolving solution [ammonium sulfate saturated at $4^{\circ} \mathrm{C}, \mathrm{pH} 3.0$, containing $1 \mathrm{mM}$ EDTA and $0.2 \%$ $(\mathrm{w} / \mathrm{v})$ charcoal], precooled to $-12{ }^{\circ} \mathrm{C}$ in an ice-salt-water bath. After $1 \mathrm{~min}$ the precipitated apoprotein and the charcoal were pelleted by centrifugation $\left(27000 \mathrm{~g},-5^{\circ} \mathrm{C}\right)$. The rotor was immediately decelerated after it reached the maximal velocity. The precipitate was redissolved in 4 volumes of 100 mM Tris- $\mathrm{HCl}$ buffer, $\mathrm{pH} 8.9$, containing $0.3 \mathrm{mM}$ EDTA and $1 \mathrm{mM}$ DTT. Charcoal was removed from the dissolved apoprotein after a 10 -min incubation at $4^{\circ} \mathrm{C}$ by centrifugation $\left(27000 \mathrm{~g}, 5 \mathrm{~min}, 4^{\circ} \mathrm{C}\right)$. The supernatant was dialyzed for 2 $\mathrm{h}$ against three changes of $20 \mathrm{mM}$ Tris- $\mathrm{HCl}$ buffer, $\mathrm{pH} 8.0$, $4^{\circ} \mathrm{C}$, containing $0.3 \mathrm{mM}$ EDTA and $1 \mathrm{mM}$ DTT.

Cyclohexanone monooxygenase from Acinetobacter NCIB was provided as a generous gift by Drs. J. Chen and C. T. Walsh (Massachusetts Institute of Technology). The apoenzyme was prepared by a slight modification of the procedure described by Mayer and Thorpe (1981) for resolution of general acyl-CoA dehydrogenase apoprotein. The resolving solution containing $0.2 \%(\mathrm{w} / \mathrm{v})$ charcoal was precooled to -12 ${ }^{\circ} \mathrm{C}$ in an ice-salt-water bath, and $30 \mu \mathrm{M}$ enzyme was added. The apoenzyme was finally dialyzed versus $100 \mathrm{mM}$ glycine-KOH, $\mathrm{pH}$ 9.0.

Reconstitution of Apoenzymes with 8-OH-5-deazaflavins. Reconstitution of pig kidney general acyl-CoA dehydrogenase apoenzyme was performed as described by Manstein et al. (1986). The other 8-OH-5-deazaflavin proteins were prepared by mixing the apoprotein with a 1.5 -fold excess of the flavin analogue. The times required for complete reconstitution of the individual apoproteins were as follows: $15 \mathrm{~min}$ at $4^{\circ} \mathrm{C}$ plus $15 \mathrm{~min}$ at $25^{\circ} \mathrm{C}$ for L-lactate oxidase; $30 \mathrm{~min}$ at $4^{\circ} \mathrm{C}$ plus $10 \mathrm{~min}$ at $25^{\circ} \mathrm{C}$ for D-amino acid oxidase; $10 \mathrm{~min}$ at 4 ${ }^{\circ} \mathrm{C}$ for cyclohexanone monooxygenase as well as MHPC. oxygenase. D-Lactate dehydrogenase was incubated at $20^{\circ} \mathrm{C}$ for $10 \mathrm{~min}$ with the flavin analogue in a buffer containing 50 $\mathrm{mM}$ potassium phosphate, $0.3 \mathrm{mM}$ EDTA, and $1 \mathrm{mM}$ DTT, $\mathrm{pH}$ 7.0. To the reconstituted D-lactate dehydrogenase a slight molar excess of $\mathrm{ZnCl}_{2}$ over protein was added. The solutions of deazaflavin-substituted proteins were concentrated to about $40 \mu \mathrm{L}$ by ultrafiltration in a Centricon- 30 microconcentrator (Amicon); the retentate was diluted with the appropriate buffer and concentrated again. This step was repeated 2 or 3 times. Finally, when unbound 8-OH-5-deazaflavin was completely removed, buffer was added to give an $\sim 20 \mu \mathrm{M}$ solution of the reconstituted protein.

Test of Stereospecificity. The absolute stereospecificity of the interaction between coenzyme and appropriate substrate was examined as described by Manstein et al. (1986). (5R)-[5- $\left.{ }^{3} \mathrm{H}\right]-8-\mathrm{OH}-5$-deazaFADH ${ }_{2}$ of $>95 \%$ steric purity was prepared by $\mathrm{NaB}^{3} \mathrm{H}_{4}$ reduction of general acyl-CoA dehydrogenase substituted with the artificial flavin. Residual borohydride was destroyed by addition of sodium pyruvate, and the solution was chromatographed over a Sephadex G-25 fine column. The chirally labeled flavin was released from the protein by heating to $100^{\circ} \mathrm{C}$ for $1 \mathrm{~min}$, followed immediately by cooling in ice and separation of the protein by centrifugation. The chiral flavin prepared by this method was bound to the apoprotein form of the enzyme whose stereochemistry was to be tested. Following the procedures described above, reoxidation was started by addition of the appropriate substrate, and the reaction was followed spectrophotometrically. After completion of the reaction an aliquot was passed 
through a Sephadex G-25 column. Each fraction was analyzed for radioactivity, and its absorption spectrum was recorded.

In some cases, another method was used for the separation of reoxidized 8-OH-5-deaza protein and reduced substrate. After completion of reoxidation, an aliquot of the reaction mixture was transferred to a Centricon-30 microconcentrator and concentrated to about $30 \mu \mathrm{L}$. The retentate was diluted with $300 \mu \mathrm{L}$ of the appropriate buffer and concentrated again. This step was repeated as long as radioactivity could be detected in the filtrate. Products of the reoxidation reaction in both filtrate and retentate were analyzed by high-pressure liquid chromatography (HPLC) on a Spectra Physics system equipped with an Altex RP-18 column $(4.6 \times 250 \mathrm{~mm})$. Chromatography was performed at $1.5 \mathrm{~mL} / \mathrm{min}$ in buffer containing $50 \mathrm{mM}$ potassium phosphate $(\mathrm{pH} \mathrm{6.0)}$ ). After 5 min of isocratic elution, a 30 -min linear gradient from 0 to $50 \%$ acetonitrile was carried out. Absorbance at $254 \mathrm{~nm}$ was measured, and $500-\mu \mathrm{L}$ fractions were collected and analyzed for radioactivity. The portion of the retentate used for HPLC analysis was brought to $5 \%(\mathrm{v} / \mathrm{v})$ in trichloroacetic acid in order to precipitate the protein and solubilize the flavin and reaction products. After being vortexed for $30 \mathrm{~s}$, the solution was centrifuged for $3 \mathrm{~min}$ in an Eppendorff bench-top centrifuge. The pellet was washed twice with $5 \%(\mathrm{v} / \mathrm{v})$ trichloroacetic acid and then dissolved in buffer containing $6 \mathrm{M}$ guanidinium hydrochloride. An aliquot of the solubilized protein was measured for radioactivity. The supernatant was adjusted to approximately $\mathrm{pH} 7$, by the addition of solid $\mathrm{NaHCO}_{3}$, and analyzed by HPLC as described above.

As an alternative to HPLC analysis, in the case of D-lactate dehydrogenase, the supernatant from heat denaturation of the separated radioactive reoxidized enzyme fraction was subjected to gel filtration through Sephadex G-25 equilibrated with 50 $\mu \mathrm{M}$ potassium phosphate, $\mathrm{pH}$ 7.0. The fractions were analyzed for radioactivity and for the characteristic fluorescence of oxidized 8-OH-5-deazaFAD (excitation at $430 \mathrm{~nm}$; emission at $490 \mathrm{~nm}$ ).

Extinction Coefficients. The extinction coefficients of 8 $\mathrm{OH}$-5-deazaFAD-reconstituted cyclohexanone monooxygenase and MHPC-oxygenase were determined by comparison of the absorbance of the flavin chromophore before and after precipitation of a $1-\mathrm{mL}$ sample with $0.1 \mathrm{~mL}$ of $50 \%$ trichloroacetic acid, followed by centrifugation to remove apoprotein and neutralization of the supernatant with solid $\mathrm{K}_{2} \mathrm{CO}_{3}$. All other extinction coefficients were determined by titration of the free analogue with apoprotein.

Buffers. If not indicated otherwise in the text, the following buffers were used: $0.1 \mathrm{M}$ glycine- $\mathrm{KOH}, \mathrm{pH} \mathrm{9.0,} \mathrm{for} \mathrm{cyclo-}$ hexanone monooxygenase; $20 \mathrm{mM}$ Tris- $\mathrm{HCl}$ containing 0.3 mM EDTA and $1 \mathrm{mM}$ DTT, $\mathrm{pH} 8.0$, for MHPC-oxygenase; $50 \mathrm{mM}$ potassium phosphate containing $0.3 \mathrm{mM}$ EDTA, $\mathrm{pH}$ 7.6 , for D-lactate dehydrogenase; $10 \mathrm{mM}$ imidazole hydro-

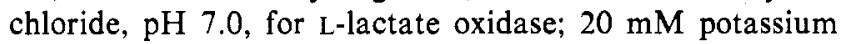
pyrophosphate, $\mathrm{pH} 8.5$, for D-amino acid oxidase.

Instrumentation. Optical spectra were recorded with a Cary 219 or Shimadzu UV-260 spectrophotometer. Fluorescence spectra were measured on a ratio-recording fluorometer built by Dr. D. P. Ballou and G. Ford of The University of Michigan. Radioactivity was determined on a Beckman LS 3801 liquid scintillation counter. The average counting efficiency was about $50 \%$.

\section{RESULTS}

Preparation of Apoproteins and Reconstitution with Flavin Analogues. Resolution of flavin from L-lactate oxidase, Dlactate dehydrogenase, D-amino acid oxidase, and general
acyl-CoA dehydrogenase was performed following well-established and published procedures (see Methods). Successful reconstitution of the apoproteins with either 8-OH-5-deazaFMN or 8-OH-5-deazaFAD has been reported previously (Manstein et al., 1986).

Cyclohexanone monooxygenase apoprotein prepared by the Mayer/Thorpe procedure had less than $0.1 \%$ residual enzymatic activity. Incubation of the apoprotein with FAD reconstituted $70 \%$ of the initial activity. Both the apoenzyme and the reconstituted 8-OH-5-deazaFAD enzyme were stable and could be stored on ice for several weeks.

The acid-ammonium sulfate procedure for reversible resolution of flavin from MHPC-oxygenase yielded apoenzyme with less than $0.05 \%$ residual enzymatic activity. About $70 \%$ of the original activity could be recovered upon incubation with the native flavin. In contrast to the observations made with 5-deazaFAD (Kishore \& Snell, 1981), MHPC-oxygenase apoenzyme, like all other apoproteins tested in this study, showed tight binding of both oxidized and reduced $8-\mathrm{OH}-5$ deazaflavin coenzymes.

Enzymatic and Spectral Properties of 8-OH-5-deazaflavin-Substituted Enzymes. 8-OH-5-deazaFAD-substituted MHPC-oxygenase shows the typical spectral and catalytic properties previously observed with the microbial flavin monooxygenases, melilotate hydroxylase, $p$-hydroxybenzoate hydroxylase, and anthranilate hydroxylase substituted with the modified deazaflavin (Manstein et al., 1986). Binding to MHPC-oxygenase apoprotein stabilizes the anionic form of the analogue. The visible absorption maximum of the free form $\left(\lambda_{\max }=430 \mathrm{~nm}, \epsilon=43600 \mathrm{~cm}^{-1} \mathrm{M}^{-1}\right)$ is shifted to 437 $\mathrm{nm}\left(\epsilon=44500 \mathrm{~cm}^{-1} \mathrm{M}^{-1}\right)$, and the oxidized chromophore is perturbed further on addition of MHPC, leading to a $5 \%$ decrease in intensity and a $2-\mathrm{nm}$ blue shift of the absorbance peak. Reoxidation of the dihydro form of the enzyme-bound analogue can be achieved by addition of MHPC plus Ac$\mathrm{PyAD}^{+}$, but not MHPC or AcPyAD ${ }^{+}$alone. Following addition of $2 \mathrm{mM} \mathrm{AcPyAD}^{+}$and $100 \mu \mathrm{M} \mathrm{MHPC}$ to a $20 \mu \mathrm{M}$ solution of the substituted enzyme at $20^{\circ} \mathrm{C}$, a half-time of approximately $10 \mathrm{~min}$ was observed for the reoxidation reaction.

Cyclohexanone monooxygenase was of interest because it represents a different type of flavoprotein monooxygenase following a Baeyer-Villiger-type reaction mechanism (Ryerson et al,, 1982). Cyclohexanone monooxygenase formed a perfectly stable complex with 8-OH-5-deazaFAD. The extinction coefficient of 8-OH-5-deazaFAD-cyclohexanone monooxygenase at its visible maximum $(434 \mathrm{~nm})$ was determined to be $47000 \mathrm{~cm}^{-1} \mathrm{M}^{-1}$. Addition of cyclohexanone did not cause any perturbation in the spectrum of the oxidized flavin analogue. A 10-fold molar excess of $\mathrm{AcPyADP}^{+}$over reduced enzyme led to a rapid $\left(t_{1 / 2}<1 \mathrm{~min}, 4^{\circ} \mathrm{C}\right)$ return of the oxidized flavin spectrum. This is consistent with the cyclohexanone substrate being unnecessary as an effector for the reduction of the native enzyme.

D-Amino acid oxidase, L-lactate oxidase, and D-lactate dehydrogenase were included in this study in order to determine whether the 8-OH-5-deazaflavin coenzyme could also serve as a probe for flavin stereospecificity in reactions catalyzed by enzymes that are supposed to follow a carbanion mechanism. Both L-lactate oxidase (Averill et al., 1975) and D-amino acid oxidase (Hersh \& Jorns, 1975; Fisher et al., 1976) had already been extensively probed with the flavin analogues 5-deazaFMN and 5-deazaFAD. Substitution with the 8$\mathrm{OH}-5$-deazaflavin coenzyme led to changes in the catalytic properties similar to those described for the 5-deazaflavin 
Table I: Determination of Chirality of Reduced $\left[5-{ }^{3} \mathrm{H}\right]-8-\mathrm{OH}-5$-deazaflavins ${ }^{a}$

\begin{tabular}{|c|c|c|c|c|}
\hline \multirow[b]{2}{*}{ enzyme } & \multirow[b]{2}{*}{ substrate } & \multicolumn{2}{|c|}{ distribution of radioactivity ${ }^{b}$} & \multirow{2}{*}{$\begin{array}{l}\text { side of flavin } \\
\text { ring interacting } \\
\text { with substrate }\end{array}$} \\
\hline & & $\begin{array}{c}\text { flavin } \\
\left(\mathrm{cpm} \times 10^{3}\right)\end{array}$ & $\begin{array}{c}\text { substrate } \\
\left(\mathrm{cpm} \times 10^{3}\right)\end{array}$ & \\
\hline 2-methyl-3-hydroxypyridine-5-carboxylic acid oxygenase & $\begin{array}{l}\text { AcPyAD }^{+} \\
\text {AcPyADP }^{+}\end{array}$ & $4.0(20)^{c}$ & $15.8(80)^{c}$ & $\begin{array}{l}\text { re } \\
r e\end{array}$ \\
\hline D-amino acid oxidase & pyruvate $/ \mathrm{NH}_{4}^{+}$ & $7.1(7)$ & $94.0(93)$ & re \\
\hline L-lactate oxidase & pyruvate & $144.8(88)$ & $21.7(12)$ & si \\
\hline D-lactate dehydrogenase & pyruvate & $61.6(93)$ & $4.4(7)$ & si \\
\hline
\end{tabular}

${ }^{a}$ Performed as described under Methods. ${ }^{b}$ After gel filtration or ultrafiltration. ${ }^{c}$ Values in parentheses are percentages.

enzymes. However, it was not possible to reduce enzymebound 8-OH-5-deazaflavin by addition of the substrates $L$ lactate and D-alanine or D-proline, respectively. This was also true when reconstituted D-lactate dehydrogenase was incubated with D-lactate. At least in part the inertness of the enzymebound 8-OH-5-deazaflavin can be attributed to its lower redox potential (Jacobson \& Walsh, 1984).

The reduced forms of the 8-OH-5-deazaflavin enzymes were prepared either by reconstitution directly with the dihydro form of the analogue or by $\mathrm{NaBH}_{4}$ reduction of the analogue after it had been bound to the apoprotein. At $4{ }^{\circ} \mathrm{C}$ and with a $10^{3}$-fold molar excess of pyruvate and ammonium ion over protein, 8-OH-5-deazaFADH ${ }_{2}-\mathrm{D}$-amino acid oxidase could be completely reoxidized, within the time of mixing, while 8-OH-5-deazaFMNH $\mathrm{H}_{2}$-L-lactate oxidase was reoxidized equally fast when pyruvate alone was added. Flavin reoxidation was also very rapid on addition of $1 \mathrm{mM}$ pyruvate to a $20 \mu \mathrm{M}$ solution of $8-\mathrm{OH}$-5-deazaFADH $\mathrm{F}_{2}-\mathrm{D}$-lactate dehydrogenase. At $4{ }^{\circ} \mathrm{C}$, reoxidation was complete within $1 \mathrm{~min}$.

Stereochemical Analysis of Enzyme-Catalyzed Hydrogen Transfer. Using the results of our previous study (Manstein et al., 1986), which had shown that reduction of 8-OH-5deazaFAD bound to general acyl-CoA dehydrogenase leads to the stereoselective incorporation of label on the $r e$ face of the flavin coenzyme, we have determined the absolute stereospecificity of five other flavoenzymes. The distribution of radioactivity is in the range found in the previous study and clearly allows determination of stereospecificity. As shown in Table I, D-amino acid oxidase, MHPC-oxygenase, and cyclohexanone monooxygenase share the re specificity with general acyl-CoA dehydrogenase and the other flavoenzymes which had been tested so far, whereas the enzymes L-lactate oxidase and D-lactate dehydrogenase interact with pyruvate at the $s i$ side of the isoalloxazine ring.

The method initially described for determination of stereochemistry (Manstein et al., 1986) has been modified in some cases, thereby improving resolution and sensitivity of the analysis. Protein and substrate were separated by ultrafiltration through Centricon-30 microconcentrators rather than by gel filtration with Sephadex G-25. This permitted the use of HPLC for better identification of products.

HPLC analysis allowed precise determination of the molecule carrying the radioactivity at any point during the stereospecificity experiment. In those cases where the tritium label was released from the flavin, it was found to be transferred specifically to the substrate. For L-lactate oxidase and D-lactate dehydrogenase, $88 \%$ and $95 \%$, respectively, of the radioactivity was associated with the modified flavin nucleotide after substrate oxidation. With D-amino acid oxidase, MHPC-oxygenase, and cyclohexanone monooxygenase, $93 \%$, $80 \%$, and $95 \%$ of the label was released as D-alanine, AcPyADH, and AcPyADPH, respectively.

Relative Accessibility of the re and si Faces of ProteinBound Flavin. The stereochemical stability of the reduced $\left[5-{ }^{3} \mathrm{H}\right]-8-\mathrm{OH}-5-$ deazaflavin coenzyme not only permits the stereochemical analysis of enzymatic reactions but can also provide information on the accessibility of the 5-position at both flavin faces, e.g. for $\mathrm{BH}_{4}^{-}$ions (Ghisla et al., 1984; Manstein et al., 1986). This should be possible for all apoproteins reconstituted so far with the 8-OH-5-deazaflavins with the exception of the Acinetobacter cyclohexanone monooxygenase, which could not be reduced with $\mathrm{NaBH}_{4}$.

When facile reduction by $\mathrm{NaBH}_{4}$ is achieved, one can readily determine if $\mathrm{NaB}^{3} \mathrm{H}_{4}$ reduction involves the same face of the flavin as reoxidation by substrate. In the present study L-lactate oxidase was used as an example. When 8-OH-5deazaFMN-L-lactate oxidase which had been reduced with $\mathrm{NaB}^{3} \mathrm{H}_{4}$ was reoxidized by addition of $30 \mathrm{mM}$ pyruvate, $90 \%$ of the radioactivity introduced by $\mathrm{NaB}^{3} \mathrm{H}_{4}$ was removed, showing that pyruvate and borohydride react with the same flavin face. That this was the si face was shown by the companion experiment in which the $(5 R)-\left[5-{ }^{3} \mathrm{H}\right]-8-\mathrm{OH}-5$-deaza$\mathrm{FADH}_{2}$ prepared by $\mathrm{NaB}^{3} \mathrm{H}_{4}$ reduction of 8-OH-5-deazaFAD-general acyl-CoA dehydrogenase was hydrolyzed to the FMN form by Naja naja venom and incorporated into the apoprotein of L-lactate oxidase. When the resulting holoenzyme was reoxidized with pyruvate, $88 \%$ of the radioactivity was found to be retained in the oxidized 8-OH-5-deazaFMN.

\section{DISCUSSION}

We have extended our studies on the stereochemistry of flavoenzyme reactions to include five new enzymes: D-amino acid oxidase, cyclohexanone monooxygenase, MHPCoxygenase, D-lactate dehydrogenase, and L-lactate oxidase. For three of these enzymes the reaction occurred on the re face of the flavin, while for D-lactate dehydrogenase and L-lactate oxidase the substrate reacted with the si face of the flavin. This is our first evidence for $s i$-side reactivity in flavoenzymes. On the basis of the data available so far, a correlation between stereospecificity and the structure of the substrate can be made. Those enzymes reacting with a pyridine nucleotide all use the $r e$ face of the flavin for this reaction. si-side stereospecificity occurs for enzymes using an $\alpha$-hydroxy acid as substrate. Further support for this concept comes from X-ray crystallographic studies on glycolate oxidase from spinach (Lindqvist $\&$ Bränden, 1985) and on flavocytochrome $b_{2}$ from bakers' yeast (Mathews \& Xia, 1987), both of which utilize the si face for reaction with their $\alpha$-hydroxy acid substrate. This is similar to the pyridine nucleotide dependent enzymes, where a correlation between stereospecificity for the $R$ or $S$ side of the pyridine ring and substrate has been reported (You et al., 1977). This result as well as our findings suggests that during evolution the catalytic machinery required for a specific enzymatic reaction has been preserved, the functional groups determining substrate specificity being adapted from one enzyme to another.

The si side specific enzymes are of particular interest. All four enzymes are irreversibly inhibited by $\alpha$-hydroxybutynoate (Schonbrunn et al., 1976; Ghisla et al., 1979a; Lederer, 1974). It should be noted that the glycolate oxidase used in the in- 


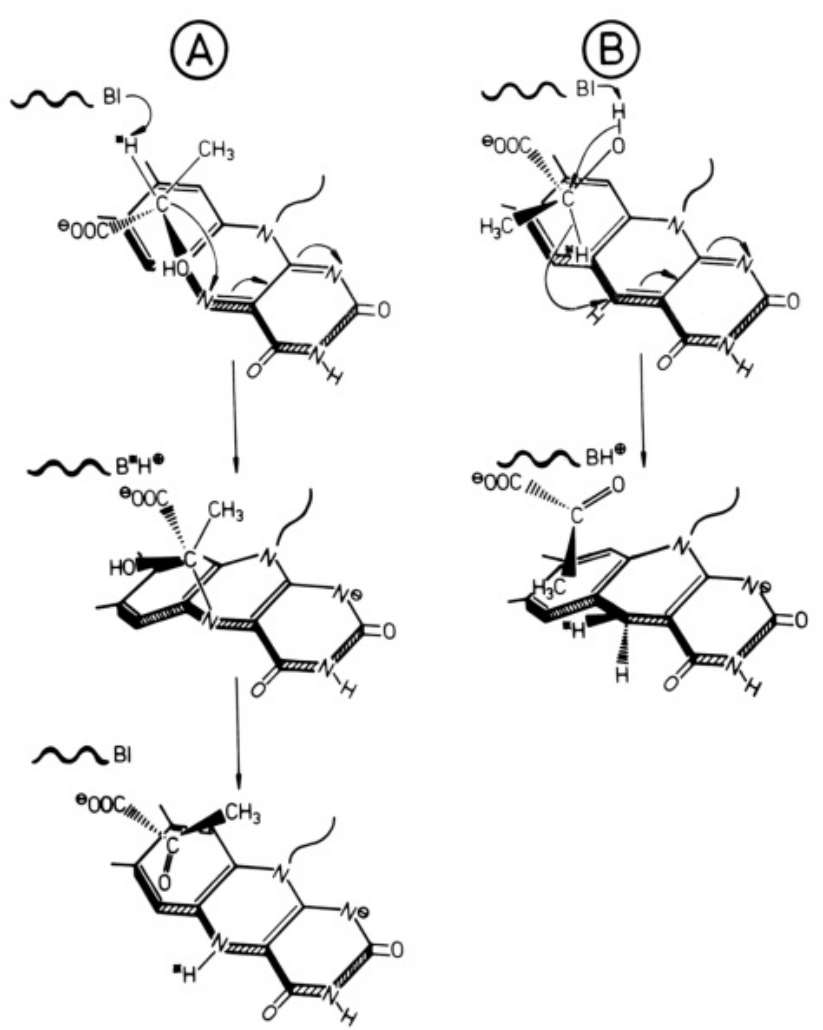

FIGURE 1: Relative orientation of substrate, flavin, and proton-abstracting base in $\alpha$-hydroxy carboxylic acid oxidizing enzymes: (A) for carbanion mechanism; (B) for hydride-transfer mechanism. For further details, see Discussion.

hibition studies was from pea seedlings, which is an L-specific enzyme closely related to glycolate oxidase from spinach for which the crystal structure was determined (Lindqvist \& Bränden, 1985).

The three L-specific enzymes (L-lactate oxidase, glycolate oxidase, and flavocytochrome $b_{2}$ ) form a flavin $\mathrm{C}(4 \alpha), \mathrm{N}(5)$ covalent adduct with this inhibitor (Schonbrunn et al., 1976; Fendrich \& Abeles, 1982; Lederer, 1974), while the D-specific enzyme D-lactate dehydrogenase reacts similarly but at positions N(5), C(6) (Ghisla et al., 1979a). On the basis of this information and general mechanistic similarities, a detailed geometry was proposed for the interaction of $\alpha$-hydroxy acid, flavin, and protein functional groups. The hypothesis was put forward that during evolution the relative orientation of substrate and flavin face was retained, but that changes in the amino acid residues governing substrate specificity occurred (Ghisla et al., 1979a, 1980). This prediction is substantiated by the present findings that the D- and L-specific $\alpha$-hydroxy acid oxidizing enzymes all use the $s i$ face of the flavin ring for catalysis.

A picture of the relative orientation of hydroxy acid substrate, flavin, and protein functional groups can be drawn. The substrate $\alpha$-position must be located close to $\mathrm{N}(5)$ of the flavin since a covalent bond is formed between the two positions in the case of L-lactate oxidase (Ghisla \& Massey, 1980) (Figure 1A). The reactivity of $\alpha$-hydroxybutynoate with the D- and L-specific enzymes, respectively, fixes the orientation of the substrate $\alpha$-carbon substituent $\left(\mathrm{CH}_{3}\right.$ for lactate) above the plane of the flavin. The carboxylate residue has been proposed to point away from $\mathrm{N}(5)$ parallel to the $\mathrm{N}(1)-\mathrm{N}(5)$ axis (Ghisla et al., 1979b). Such a description was proposed earlier for D-lactate dehydrogenase and L-lactate oxidase. In those cases the $r e$ face was arbitrarily chosen as the one reacting with substrate (Ghisla et al., 1980). This clearly has to be revised in light of the new information presented here.

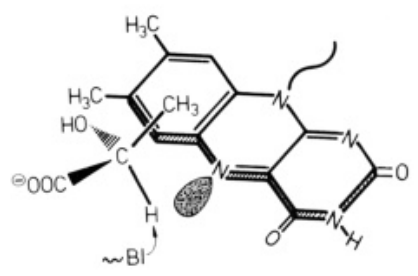

FIGURE 2: Alternative orientation of substrate, flavin, and protein base. This alignment would make it difficult to differentiate between hydride-transfer mechanism and carbanion mechanism. See also Discussion.

The current assumption for the mechanism of this class of enzymes envisages a carbanion mechanism (Bruice, 1980; Walsh, 1980; Massey \& Ghisla, 1983). Intake of electrons and in particular formation of a covalent bond, as in the case of glycolate reacting with L-lactate oxidase, must occur via the N(5) $\pi$-orbital above the flavin plane. Substrate should thus be placed parallel to and above the flavin $s i$ face. This is in agreement with the location of an inhibitor in the case of the crystallographic structure of glycolate oxidase (Lindqvist \& Bränden, 1985). On the other hand it has been established with 5-deazaflavin-substituted enzymes that the substrate $\alpha$-hydrogen is transferred to the deazaflavin $\mathrm{C}(5)$ position (Hersh \& Jorns, 1975; Averill et al., 1975; Fisher et al., 1976). As pointed out previously (Ghisla, 1982), this poses an evident dilemma: If the substrate $\alpha$-hydrogen is placed as shown in Figure 1A, i.e., on the substrate face distal to the flavin, then it is difficult to envisage the transfer of the abstracted proton from the base to the flavin 5-position. A solution of this dilemma exists if one assumes two distinctly different mechanisms, one for the normal flavin (carbanion mechanism, Figure 1A) and another one for deazaflavin (hydride-transfer mechanism, Figure 1B). This would require opposite orientations for the $\alpha$-hydroxy and $\alpha$-alkyl substituent of bound substrate for the two mechanisms. It should be noted that substrate binding is a rapid, freely reversible process and that binding of D-lactate to L-lactate oxidase is tighter than binding of the $\mathrm{L}$ form, which is the substrate (Sullivan, 1968). The substrate orientations required are shown in Figure 1. For the hydride mechanism, the substrate would need to be inserted with the $\alpha$-hydrogen sandwiched between the $\mathrm{C} \alpha$ of lactate and the 5-position of the flavin. The base might serve in abstracting the $\alpha-\mathrm{OH}$ proton (Figure 1B).

An alternative explanation which might resolve the dilemma would be to have the substrate $\alpha$-hydrogen oriented toward the face of the flavin. This would require that the base abstracting the $\alpha$-hydrogen is close to $\mathrm{N}(5)$, roughly in plane with the flavin (Figure 2). In the carbanion mechanism, $\mathrm{C} \alpha$ proton abstraction would be followed by rapid electron transfer to the flavin and transfer of the $\mathrm{C} \alpha$ proton to the $\mathrm{N}(5)$ position. Space-filling models suggest that accommodation of both a monofunctional base and the substrate around the flavin N(5) position is possible. Such a juxtaposition of reactants would make it difficult to differentiate between a hydride-transfer and a carbanion mechanism. We will try to solve this intriguing problem by determining the orientation of the third substituent of $\alpha$-hydroxy carboxylic acids with respect to the flavin. This might be achieved by the use of appropriately modified flavins and substrates.

\section{ACKNOWLEDGMENTS}

We thank Dr. L. M. Schopfer for many helpful discussions. We also thank Dr. Pierre Brissette for samples of 2-methyl3-hydroxypyridine-5-carboxylic acid and its oxygenase and Drs. J. Chen and C. T. Walsh (Massachusetts Institute of Technology) for a sample of cyclohexanone monooxygenase. 
Registry No. MHPC-oxygenase, 37256-69-2; FAD, 146-14-5; FMN, 146-17-8; D-amino acid oxidase, 9000-88-8; L-lactate oxidase, 9028-72-2; D-lactate dehydrogenase, 9028-36-8; cyclohexanone monooxygenase, 52037-90-8.

\section{REFERENCES}

Ashton, W. T., \& Brown, R. D. (1980) J. Heterocycl. Chem. 17, 1709-1712.

Averill, B. A., Schonbrunn, A., Abeles, R. H., Weinstock, L. T., Cheng, C. C., Fisher, J., Spencer, R., \& Walsh, C. (1975) J. Biol. Chem. 250, 1603-1605.

Bruice, T. C. (1980) Acc. Chem. Res. 13, 256-262.

Choong, Y. S., Shephard, M. G., \& Sullivan, P. A. (1975) Biochem. J. 145, 37-45.

Curti, B., Ronchi, S., Branzoli, U., Ferri, G., \& Williams, C. H., Jr. (1973) Biochim. Biophys. Acta 327, 266-273.

Fendrich, G., \& Abeles, R. H. (1982) Biochemistry 21, 6685-6695.

Fisher, J., Spencer, R., \& Walsh, C. (1976) Biochemistry 15, 1054-1064.

Ghisla, S. (1982) in Flavins and Flavoproteins (Massey, V., \& Williams, C. H., Jr., Eds.) pp 133-142, Elsevier/ North-Holland, New York.

Ghisla, S., \& Massey, V. (1980) J. Biol. Chem. 225, 5688-5696.

Ghisla, S., Olson, S. T., Massey, V., \& Lhoste, J.-M. (1979a) Biochemistry 18, 4733-4742.

Ghisla, S., Massey, V., \& Choong, Y. S. (1979b) J. Biol. Chem. 254, 10662-10669.

Ghisla, S., Lhoste, J.-M., Olson, S. T., Whitfield, C., \& Massey, V. (1980) in Flavins and Flavoproteins (Yagi, K., \& Yamano, T., Eds.) pp 131-138, Japan Scientific Society Press, Tokyo.

Ghisla, S., Thorpe, C., \& Massey, V. (1984) Biochemistry 23, 3154-3161.

Hersh, L. B., \& Jorns, M. S. (1975) J. Biol. Chem. 250, 8728-8734

Jacobson, F., \& Walsh, C. (1984) Biochemistry 23, 979-988.

Kishore, G. M., \& Snell, E. E. (1981) J. Biol. Chem. 256, 4234-4240.

Lederer, F. (1974) Eur. J, Biochem. 46, 393-399.

Lindquist, Y., \& Brändēn, C.-I. (1985) Proc. Natl. Acad. Sci. U.S.A. 82, 6855-6859.
Manstein, D. J., \& Pai, E. F. (1986) J. Biol. Chem. 261, 16169-16173.

Manstein, D. J., Pai, E. F., Schopfer, L. M., \& Massey, V. (1986) Biochemistry 25, 6807-6816.

Massey, V., \& Curti, B. (1966) J. Biol. Chem. 241, 3417-3423.

Massey, V., \& Ghisla, S. (1983) in Biological Oxidations (Sund, H., \& Ullrich, V., Eds.) pp 114-139, Springer, Berlin.

Mathews, F. S., \& Xia, Z.-X. (1987) in Flavins and Flavoproteins (Edmondson, D. E., \& McCormick, D. B., Eds.) pp 123-132, de Gruyter, Berlin and New York.

Mayer, E. J., \& Thorpe, C. (1981) Anal. Biochem. 116, 227-229.

Olson, S. T., \& Massey, V. (1979) Biochemistry 18, 4714-4724.

Pai, E. F., \& Schulz, G. E. (1983) J. Biol. Chem. 258, 1752-1758.

Ryerson, C. C., Ballou, D. P., \& Walsh, C. (1982) Biochemistry 21, 2644-2655.

Schonbrunn, A., Abeles, R. H., Walsh, C. T., Ghisla, S., Ogata, H., \& Massey, V. (1976) Biochemistry 15, 1798-1807.

Spencer, R., Fisher, J., \& Walsh, C. (1976) Biochemistry 15, 1043-1053.

Sullivan, P. A. (1968) Biochem. J. 110, 363-371.

Sullivan, P. A., Choong, Y. S., Schreuers, W. A., Cutfield, J. F., \& Shephard, M. G. (1977) Biochem. J. 165, 375-383.

Swoboda, B. E. P. (1969) Biochim. Biophys. Acta 175, 365-379.

Swoboda, B. E. P., \& Massey, V. (1965) J. Biol. Chem. 240, 2209-2215.

Thorpe, C., Matthews, R. G., \& Williams, C. H., Jr. (1979) Biochemistry 18, 331-337.

Walsh, C. (1980) Acc. Chem. Res. 13, 148-155.

Yamazaki, S., Tsai, L., Stadtman, T. C., Jacobson, F. S., \& Walsh, C. (1980) J. Biol. Chem. 255, 9025-9027.

Yamazaki, S., Tsai, L., Stadtman, T. C., Teshima, T., Nakaji, A., \& Shiba, T. (1985) Proc. Natl. Acad. Sci. U.S.A. 82, 1364-1366.

You, K. S., Arnold, L. J., Jr., \& Kaplan, N. O. (1977) Arch. Biochem. Biophys. 180, 550-554. 